International Journal of Engineering \& Technology, $7(4.20)(2018) 578-583$
Sinternational Journal of Engineering \& Technology
Website www.sciencepubco.com/index.php/IJET
Research paper

\title{
Mapping Climate Changes in Iraq By Using Geographical Information System (GIS)
}

\author{
Zainab Sahib Jawad ${ }^{1 *}$, Fatima Asaad Tayeb ${ }^{1}$, Ahmed Kareem Jebur ${ }^{1}$ \\ ${ }^{\text {IDepartment }}$ of Surveying Techniques, Kut Technical Institute, Middle Technical University, Baghdad, Iraq \\ *Corresponding author E-mail: zainab_sahib@yahoo.com
}

\begin{abstract}
The Trapped sun's thermal radiation in the earth's atmosphere is known as the greenhouse effect. This process is considered very important since it keeps the earth warm and hence possible to live in. Greenhouse gases such as carbon dioxide $\left(\mathrm{CO}_{2}\right)$ and methane $\left(\mathrm{CH}_{4}\right)$ are considered very important contributors to the greenhouse effect. During the last two decades, the level of greenhouse gases has increased, which plays a major role in global warming and climate change. The Middle East is considered among the most affected areas by climate change. In the current study, Geographical Information System (GIS) has been used to create some temperature maps that could show the air temperature distribution and difference between two different periods of time (past and recent) in different stations that cover the Iraqi governorates. A spatial interpolation method has been used. This method considers known values of temperature at a given location (stations in the current study) to estimate a continuous surface map during a specific period of time. The results of this study showed no significant increase in the average air temperature values, however the area of high air temperature values is growing during the cold and hot months of the year.
\end{abstract}

Keywords: Air temperature, Climate change, Geographical Information System (GIS), Global warming, Iraq

\section{Introduction}

In order to fully understand all the aspects related to global warming and how it is developing, it is important to understand the meaning of the greenhouse effect and why it is important to earth. As the sun supplies our earth with energy, one third of that energy is reflected back to space by the top of the earth's atmosphere. The earth's surface and some atmospheric greenhouse gases absorb the remaining energy. In order to balance that absorbed energy, earth radiates some energy to space. Clouds absorb some of this radiation and reflect the remaining back to the surface (Akitt, 2018). This whole process is known as the greenhouse effect, which can be defined briefly as the trapping of the sun's thermal radiation in the earth's atmosphere. This process is considered very important because it warms the earth up and thus makes life possible. It is believed that the earth's surface temperature would be below the freezing point of water without the natural greenhouse effect. However, recently the natural greenhouse effect has intensified, causing what is known as global warming (Oktyabrskiy, 2016, Akitt, 2018).

The atmospheric greenhouse gases include water vapor $\left(\mathrm{H}_{2} \mathrm{O}\right)$, carbon dioxide $\left(\mathrm{CO}_{2}\right)$, methane $\left(\mathrm{CH}_{4}\right)$, nitrous oxide $\left(\mathrm{N}_{2} \mathrm{O}\right)$, chlorofluorocarbons (CFCs), hydrofluorocarbons (HFCs), and perfluorocarbons (PFCs) (Freije \& Salman, 2017). They play a major role in the greenhouse effect because they absorb the energy radiated from the earth and trap it in the atmosphere. Carbon dioxide $\left(\mathrm{CO}_{2}\right)$ is considered the main contributor to the enhanced greenhouse gas effect accounting for about $80 \%$ of the total greenhouse gas emissions worldwide (Freije \& Salman, 2017). Combustion of fossil fuels and human activities, such as transportation and residential heating and cooling, are considered the main reasons for carbon dioxide emissions to the atmosphere. It is believed that $\mathrm{CO}_{2}$ could stay in the earth's atmosphere for about 50 to 200 years. Global warming can be defined as an increase in the temperature of the earth's surface due to the increased emissions of greenhouse gases to the atmosphere. It can be explained as the sun's heat passes through the glass of a closed vehicle. The trapped energy then cannot pass back through the vehicle's glass, which makes the car warmer. The increased level of carbon dioxide is considered the main reason for global warming because $\mathrm{CO}_{2}$ is acting as a blanket, trapping more heat in the earth's atmosphere (Freije \& Salman, 2017). It has been reported that the atmospheric level of $\mathrm{CO}_{2}$ has increased from 312 parts per million in 1958 to 411.31 part per million in 2018 (www.CO ${ }_{2}$ earth). The safe atmospheric level of $\mathrm{CO}_{2}$ is 350 parts per million and it has become higher than that since 1988. Figure 1 shows the $\mathrm{CO}_{2}$ atmospheric concentrations (from 1958 to 2018) in parts per million and it is clear that the current level of $\mathrm{CO}_{2}$ in the atmosphere is higher than any other time. The main reasons for the increased atmospheric level of $\mathrm{CO}_{2}$ are natural processes, such as volcanic eruptions, and human activities. Melting glaciers around the world, warming oceans and sea level rise, extreme events, such as floods and hurricanes, and Ozone Depletion are considered the main proves of global warming (Awanthi and Navaratne, 2018). The Middle East is considered among the most affected areas by climate change (Bucchignani et al. 2018). 


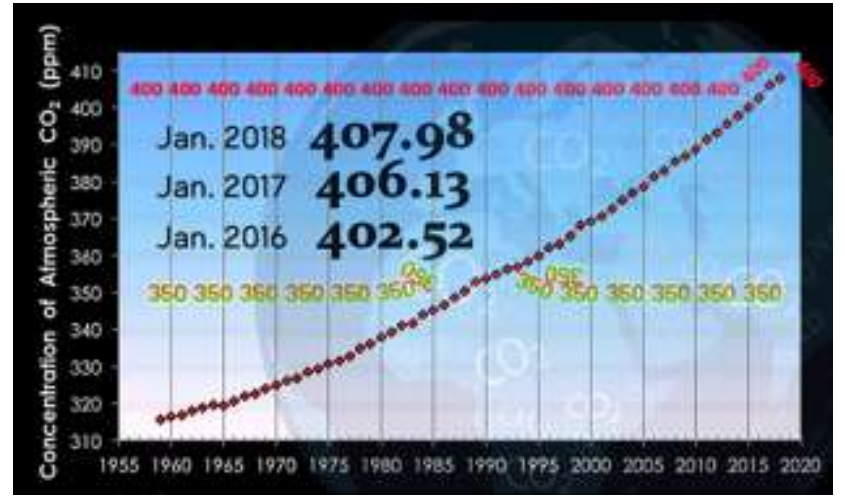

Fig. 1: Atmospheric $\mathrm{CO}_{2}$ concentrations for the period (1958 to 2018) (www. $\mathrm{CO}_{2}$.earth)

\section{Problem Statement and Methodology}

The study was conducted to illustrate the air temperature distribution and difference along stations that are distributed across the area of study (Iraq) in order to show the effect of climate patterns. For that reason air temperature maps have been created.

\subsection{Climate data}

Air temperature data that are used in the current study were obtained from the Global Historical Climatology Network version 2 for the period of 1980 to 2014. The website provide the data of about 830 stations that covers the 18 provinces in Iraq.

\subsection{Program and Data analysis}

Geographical Information System (GIS) is considered as a very useful tool when it comes to creating and testing models that could demonstrate any kind of data in an understandable way. It was designed to handle various types of geographic information techniques. Additionally, the capability of GIS in analyzing spatial relationships made it a very unique research program. GIS has been used in the study in order to create some temperature maps that could show air temperature distribution and difference between two different periods of time (past and recent) in different stations that cover the Iraqi governorates. Three different years that are 1980, 2004, and 2014 have been chosen in order to illustrate the average air temperature distribution across the area of interest. Additionally, temperature distribution has been shown by creating some maps for the hot months of the year, that are June, July, and August, and the cold months, that are December, January, and February. Furthermore, average annual temperature of the mentioned three years $(1980,2004$, and 2014) have been also displayed. In order to present the changes in temperature, average annual temperature difference for the period of (2004 to 2014) has been also clarified.

\section{Study Area}

The study area of the presented study is Iraq, which is a Middle Eastern country that covers an area of 437,072 square kilometer. Iraq combines four main geographical sections which are the western and south west desert, the upland, the northern highlands, and the alluvial which extends from Baghdad to the south of the country (Abdul-Kareem et al, 2013).

In order to create some maps that illustrate the average air temperature across Iraq during different months for different years, air temperature data from around 830 stations have been considered. These stations cover all the provinces of Iraq from north to south. The dots in figure 2 show the stations provided by the Global Historical Climatology Network version 2.

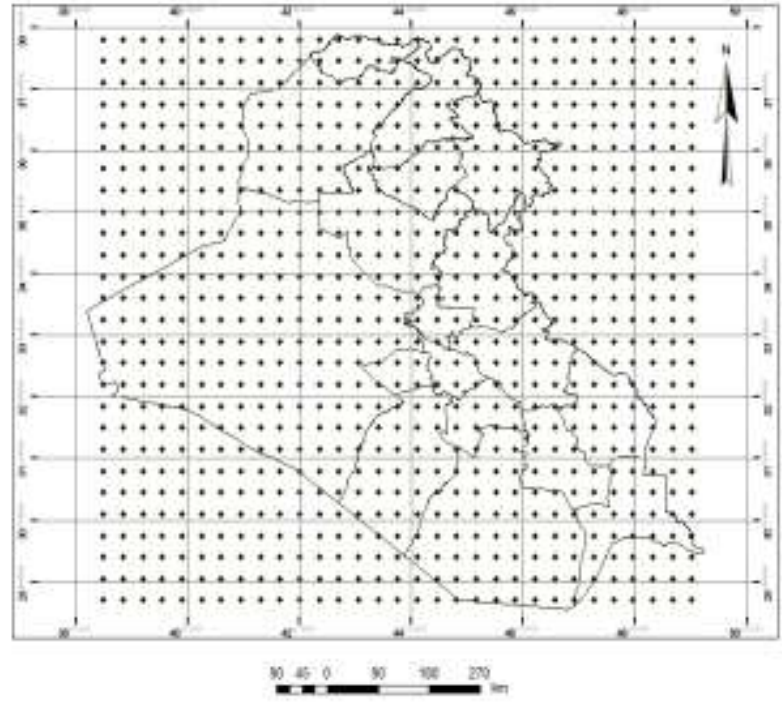

Fig. 2: Stations Position

\section{Results and Discussion}

In the current study, number of maps have been created based on temperature data that have been obtained. A spatial interpolation method has been used. This method considers known values of temperature at a given location (stations in the current study) to estimate a continuous surface map during a specific period of time. There are several types of spatial interpolation that are inverse distance weighting (IDW), spline, and Kriging. Spatial interpolation is useful in a wide variety of contexts such as estimating rainfall, groundwater pollution, temperature, or the spread of a disease. It is perfect at 'fill in the gaps' between known data of some stations. In this study Kriging method was used to generate a continuous surface of temperature distribution maps in the study area (Iraq) based on climate data. These maps can be used to estimate, interpret, and analyse climate changes over a specific period of time. The temperature data showed a significant variation in different regions across the area of study (Iraq). Figures 3 through 5 represent the average air temperature of the coldest months of the year that are December, January, and February. Figure 3 (a, b, and c) show the average temperature of December for the years of 1980, 2004, and 2014 respectively. Figure 4 (a) shows the average temperature of January for the year of 1980 , the average temperature in the north ranges from -1.31 to $6.36{ }^{\circ} \mathrm{C}$ which is represented by the green color on the map. On the other hand, the average temperature in the south of Iraq ranges from 12.74 to $17.16{ }^{\circ} \mathrm{C}$ which is symbolized by the red and orange color. It is clear from the figures that there is no significant increase in air temperature values when the average air temperature of 1980 was compared to 2004. While, there is some significant changes in temperature patterns when comparing 2004 with 2014. As it is shown in figure 4 (b and c), the orange and red areas which represents the air temperature of 12.74 to $17.16{ }^{\circ} \mathrm{C}$ have extended to cover larger area. On the other hand, the green color which represents an air temperature of 1.94 to $8.89{ }^{\circ} \mathrm{C}$ in the north provinces has decrease to a smaller area. Furthermore, during 2014 no degrees of negative temperature were recorded when it was compared to 1980. Figures $5(\mathrm{a}, \mathrm{b}$, and $\mathrm{c})$ shows the air temperature of February for the years of 1980, 2004, and 2014 respectively. 


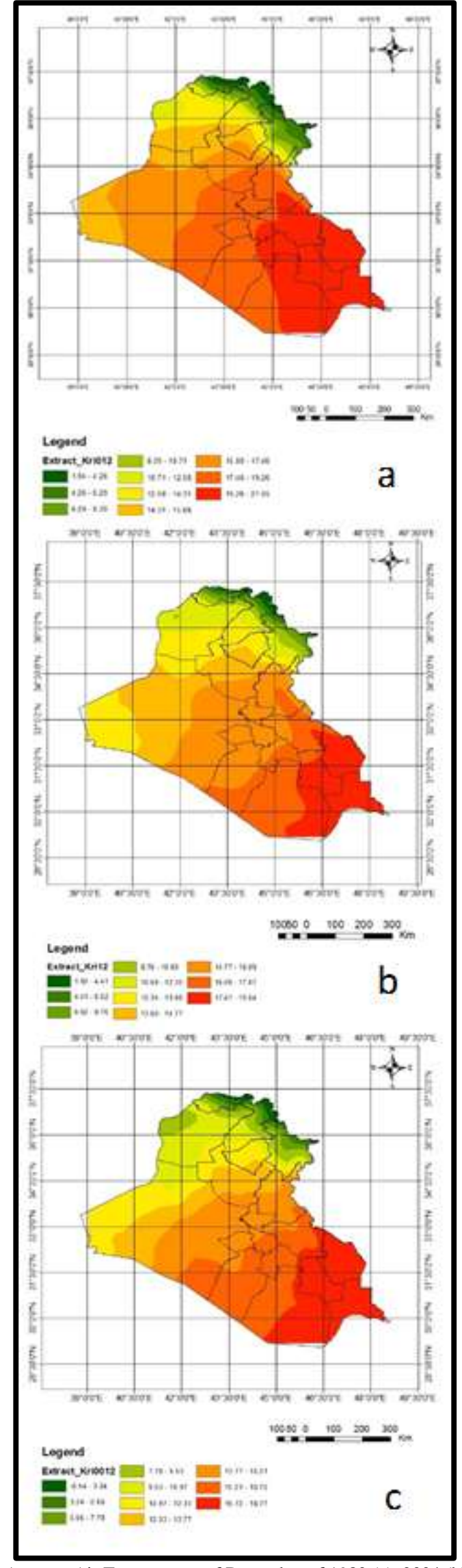

Fig. 3: Average Air Temperature of December of 1980 (a), 2004 (b), and 2014 (c)

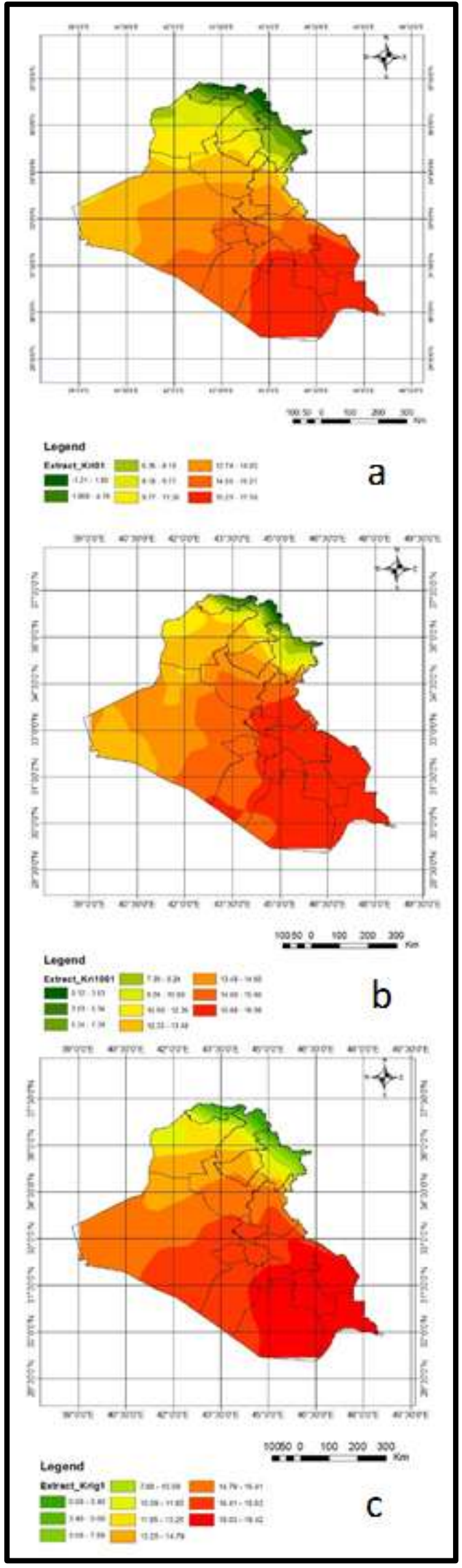

Fig. 4: Average Air Temperature of January of 1980 (a), 2004 (b), and 2014 (c) 


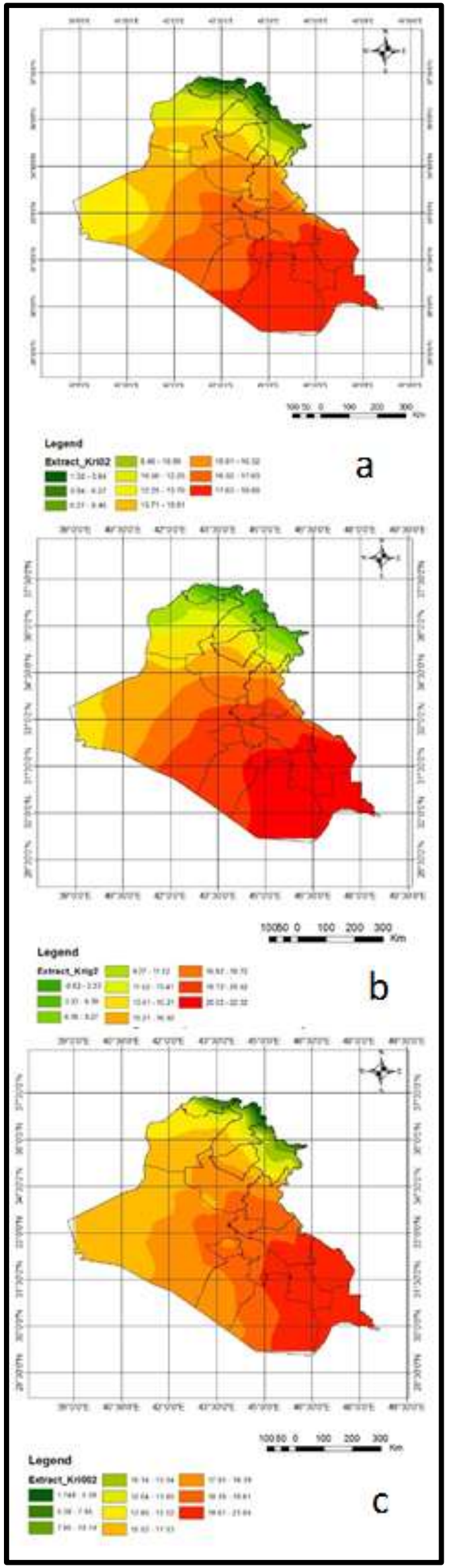

Fig. 5: Average Air Temperature of February of 1980 (a), 2004 (b), and 2014 (c)
Figures 6 through 8 represent the average air temperature of the hottest months of the year that are June, July, and August for the years of 1980, 2004, and 2014 respectively. It is clear from the figures that the coverage area of temperature that ranges between 44 and $49{ }^{\circ} \mathrm{C}$ has extended when comparing 2004 with 2014 and that affect most of the provinces in the south. Average air temperature ranges of 33 to $40{ }^{\circ} \mathrm{C}$ and 40 to $44{ }^{\circ} \mathrm{C}$ have followed the same scenario. However, there is no noticeable increase in the average air temperature of 2004 when it was compared to 1980 . Multiple reasons could explain the change in temperature such as decline of vegetation which needs further research.

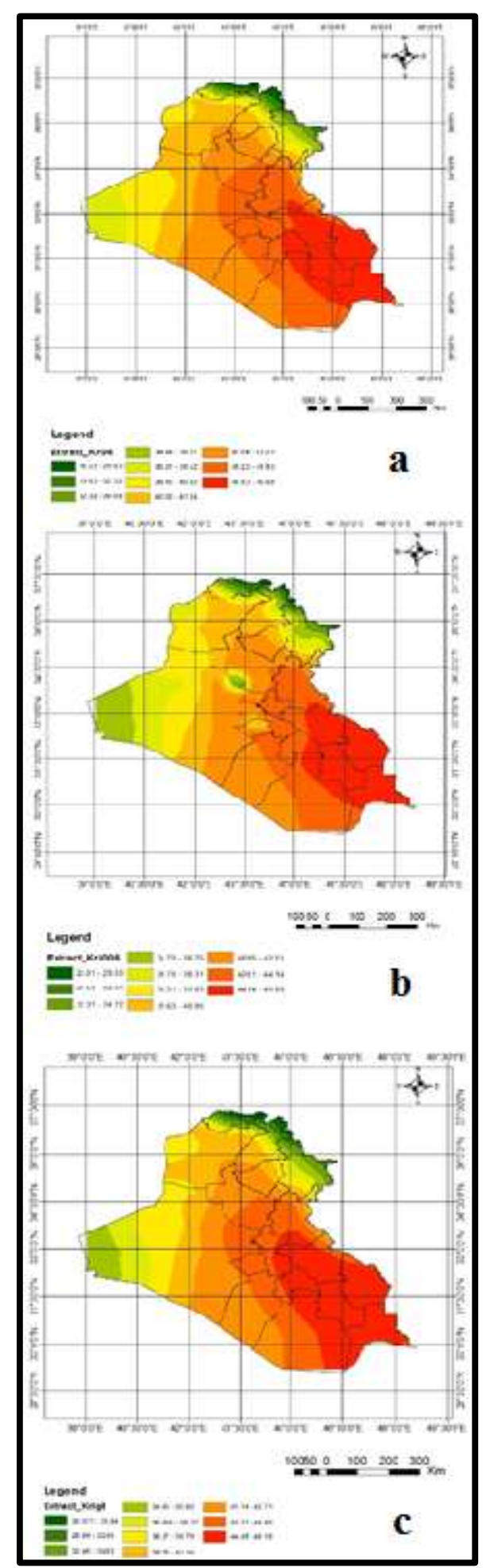

Fig. 6: Average Air Temperature of June of 1980 (a), 2004 (b), and 2014 (c) 


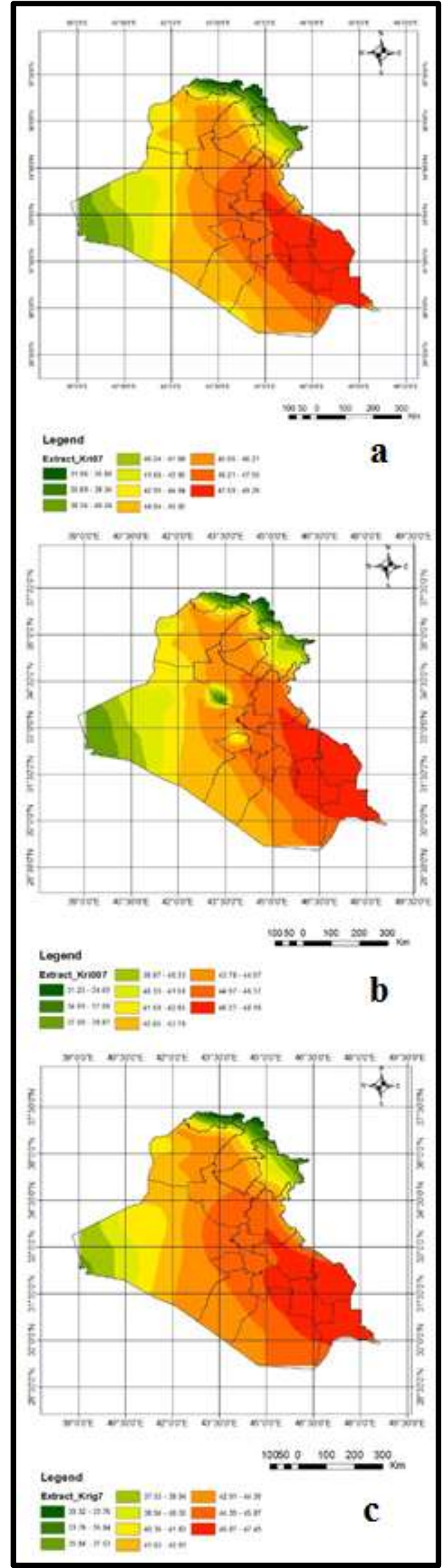

Fig. 7: Average Air Temperature of July of 1980 (a), 2004 (b), and 2014 (c)

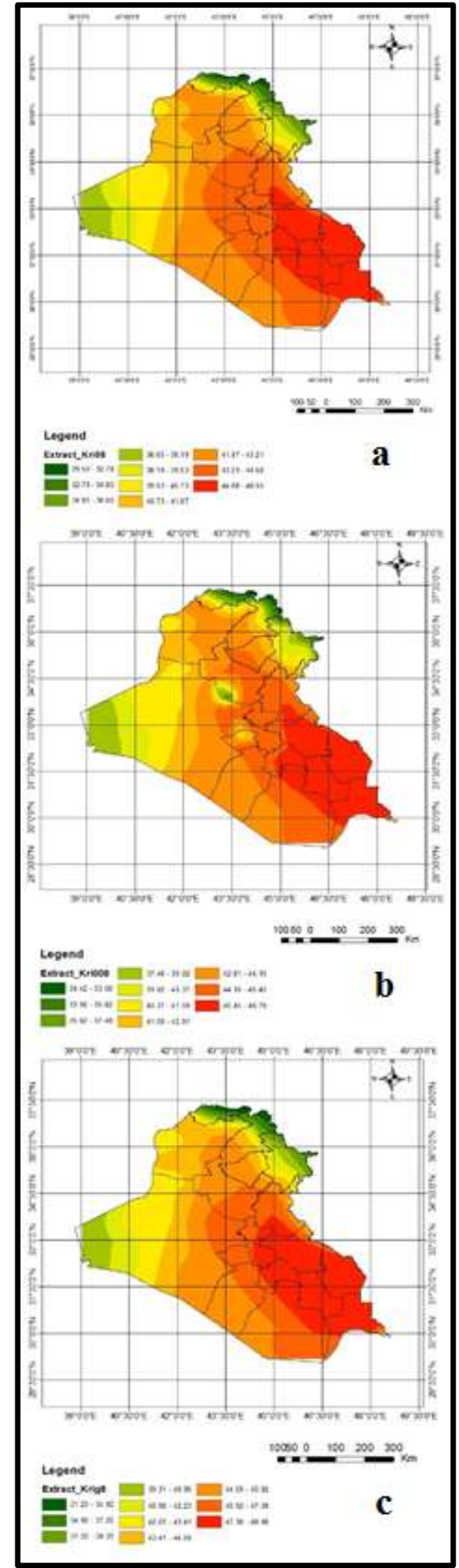

Fig. 8: Average Air Temperature of August of 1980 (a), 2004 (b), and 2014 (c)

Figure $9(\mathrm{a}, \mathrm{b}$, and c) demonstrates the annual average temperature of the years 1980, 2004, and 2014 respectively. Figures 10 shows the annual average temperature difference between 2004 and 2014 It is can be noticed that most of the Iraqi provinces are witnessing 
some temperature change even though it is not that high, but the affected area is getting larger. More research can be done to fully understand the reasons behind temperature changes and other factors can be taken into consider, such as precipitation and vegetation patch, in order to seek solutions. It is vital to raise awareness among people when it comes to climate change because the most effective ways to reduce $\mathrm{CO}_{2}$ level in the earth atmosphere are related to human activities such as: saving hot water, planting trees, recycling, walking for small distances or using public transportation, using cold water to clean clothes, setting thermostat down a few degrees in the winter, turning off the lights when leaving a room. The capture and storage of $\mathrm{CO}_{2}$ in different geologic formations, such as coal seams, deep saline aquifers, and depleted oil and gas reservoirs, is considered another modern effective way of reducing $\mathrm{CO}_{2}$ levels in the atmosphere.

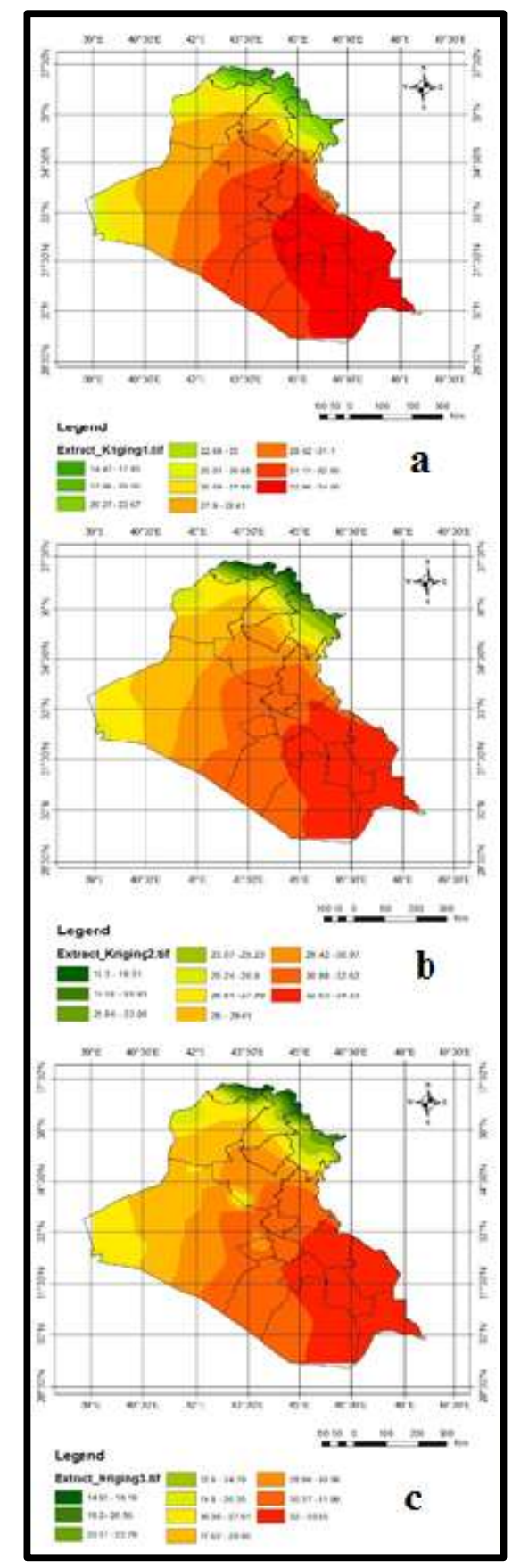

Fig. 9: Annual Average Temperature of 1980 (a), 2004 (b), and 2014 (c)

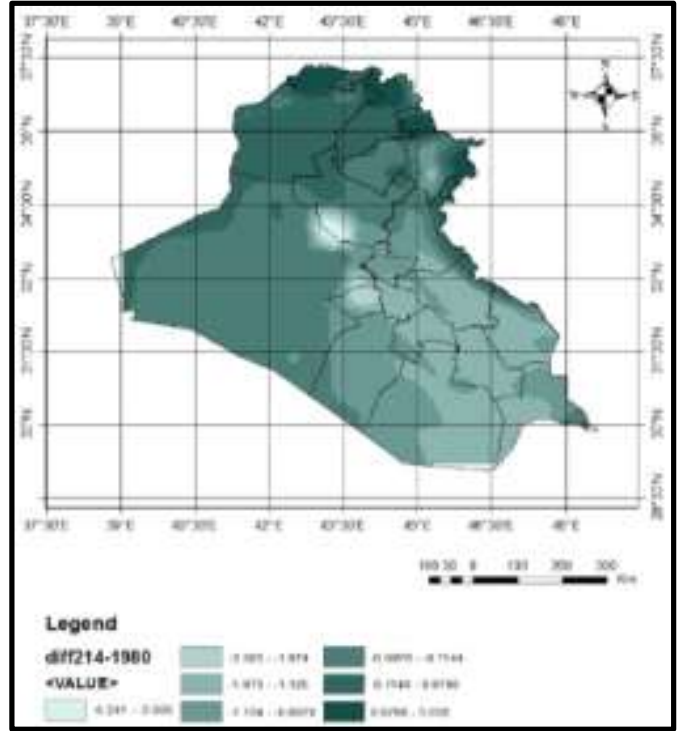

Fig. 10: Annual average temperature difference between 2004 and 2014

\section{Conclusion}

In the current study, Geographical Information System (GIS) (version10.5) has been used to create some temperature maps that could show the temperature distribution and changes in different stations that cover the Iraqi governorates. The results of this study showed a difference in the temperature of the compared years $(1980,2004$, and 2014) when it comes to the area of coverage. For instance during the cold months of the year, the temperature ranges from 12.74 to $17.16{ }^{\circ} \mathrm{C}$ has extended to cover larger areas. Moreover, during the hot months, the coverage area of temperature that ranges between 44 and $49{ }^{\circ} \mathrm{C}$ has extended when comparing 2004 with 2014 and that affect most of the provinces in the south. Average air temperature ranges of 33 to $40{ }^{\circ} \mathrm{C}$ and 40 to 44 ${ }^{\circ} \mathrm{C}$ have followed the same scenario. In conclusion, the results of this study showed a growing area of high average air temperature with no significant increase or change in temperature values.

\section{References}

[1] Abdul-Kareem, A. K., Al-Timim, A. I., \& Al-Jumaily, K. (2013), Estimated the Seasonal Change of Temperature in Iraq Using GIS Techniques. Iraqi Journal of Science, 54(4), 975-982.

[2] Akitt, J. W. (2018), Some observations on the greenhouse effect at the Earth's surface. Spectrochimica Acta Part A: Molecular and Biomolecular Spectroscopy, 188, 127-134.

[3] Awanthi, M. G. G., \& Navaratne, C. M. (2018), Carbon Footprint of an Organization: a Tool for Monitoring Impacts on Global Warming. Procedia engineering, 212, 729-735.

[4] Bucchignani, E., Mercogliano, P., Panitz, H. J., \& Montesarchio, M. (2018). Climate change projections for the Middle East-North Africa domain with COSMO-CLM at different spatial resolutions. Advances in Climate Change Research, 9(1), 66-80.

[5] Freije, A. M., Hussain, T., \& Salman, E. A. (2017). Global warming awareness among the University of Bahrain science students. Journal of the Association of Arab Universities for Basic and Applied Sciences, 22(1), 9-16.

[6] Oktyabrskiy, V. P. (2016). A new opinion of the greenhouse effect. St. Petersburg Polytechnical University Journal: Physics and mathematics, 2(2), 124-126.

[7] www.CO.earth. 